\title{
Chromosome-level analysis of the Mauremys mutica genome reveals adaptation of temperature-dependent sex-associated genes
}

\author{
Xinping Zhu ${ }^{1}$, Xiao Li Liu ${ }^{2}$, Yakun Wang ${ }^{3}, \mathrm{Ju}$ Yuan ${ }^{3}$, Fang Liu ${ }^{3}$, Xiaoyou Hong ${ }^{3}$, Wei Li ${ }^{3}$, \\ Chen $\mathrm{Chen}^{3}$, Lingyun $\mathrm{Yu}^{3}$, Wei $\mathrm{Ni}^{3}$, Haiyang $\mathrm{Liu}^{4}$, Jian $\mathrm{Zhao}^{3}$, Chengqing $\mathrm{Wei}^{3}$, Haigang \\ $\mathrm{Chen}^{3}$, and Yihui $\mathrm{Liu}^{3}$ \\ ${ }^{1}$ Pearl River Fisheries Research Institute, Chinese Academy of Fishery Sciences \\ ${ }^{2}$ Institute of Hydrobiology Chinese Academy of Sciences \\ ${ }^{3}$ Affiliation not available \\ ${ }^{4}$ Chinese Academy of Fishery Sciences Pearl River Fisheries Research Institute
}

September 29, 2021

\begin{abstract}
Knowledge of the sex determination system and sex-associated genes has important implications in physiology, ecology and evolution, but the mechanisms underlying sexual determination systems in turtles has not been fully elucidated, due to their remarkable variability and a lack of reference genomes in some species. In this report, we describe the first genome assembled at the chromosome scale for Mauremys mutica using Illumina and high-throughput chromatin conformation capture (Hi-C) technology. A total of $280.42 \mathrm{~Gb}$ of clean data were generated using the Pacific Biosciences platforms, which represented approximately $119 \times$ coverage of the Mauremys mutica genome. The assembly comprised $2.23 \mathrm{~Gb}$ with a contig N50 of 8.53 $\mathrm{Mb}$ and scaffold N50 of $141.98 \mathrm{Mb}$. Genome Hi-C scaffolding resulted in 26 pseudochromosomes containing $99.98 \%$ of the total assembly. Genome annotation predicted 24,751 protein-coding genes, and $97.23 \%$ of them were annotated. Comparative genomics analysis indicated that the lizard-snake-tuatara clade diverged from the bird-crocodilian-turtle clade at approximately 283.1-320.5 Mya. Additionally, positive selection of genes and gene families related to calcium signaling, neuroactive ligandreceptor interaction, and expansion of the hormone signaling pathway were identified, implicating their roles of sex regulation inMauremys mutica. High-quality genome assembly may provide a valuable genomic resource for further research investigating gene-environment interactions in Mauremys mutica.
\end{abstract}

\section{Hosted file}

Submitted-Manuscript20210831.docx available at https://authorea.com/users/438552/articles/ 539739-chromosome-level-analysis-of-the-mauremys-mutica-genome-reveals-adaptation-oftemperature-dependent-sex-associated-genes 


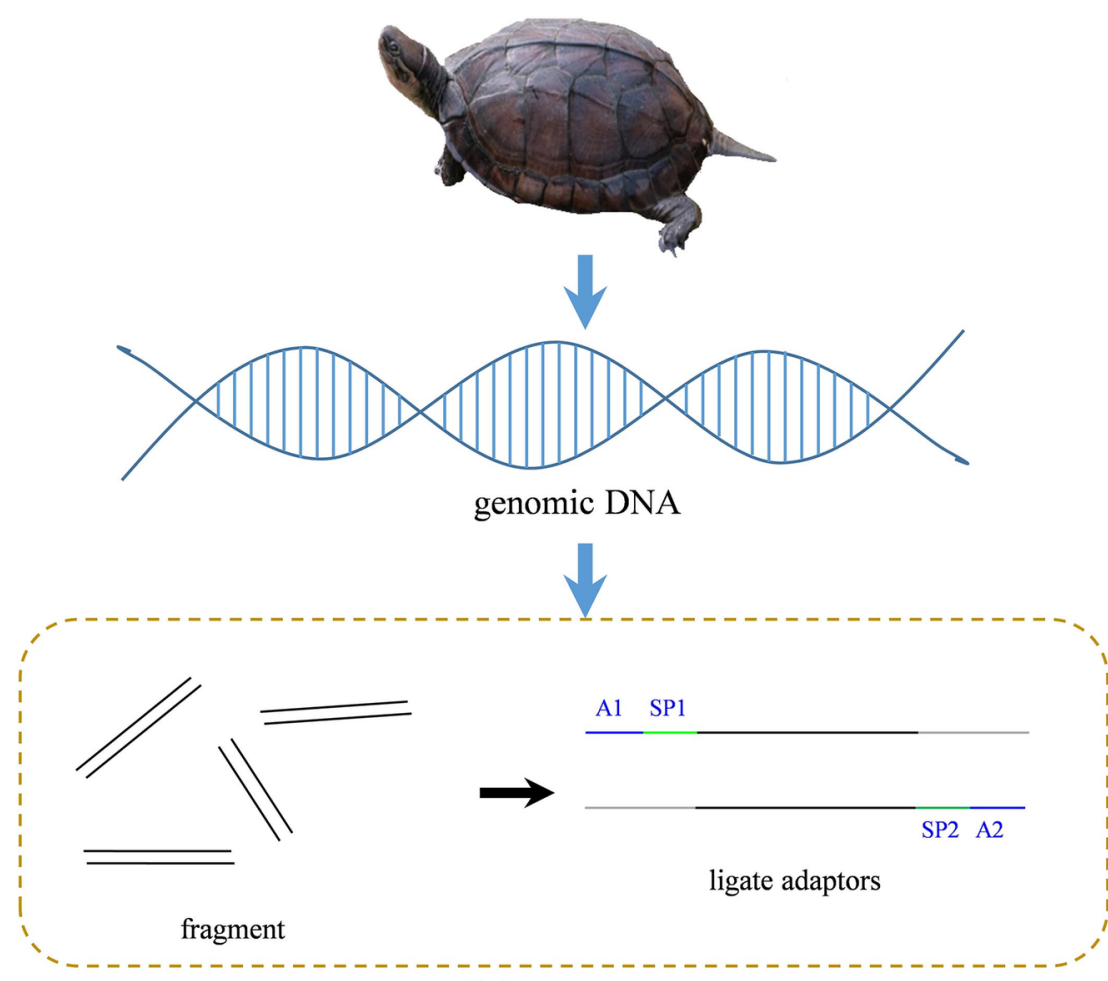

liabrary preparation

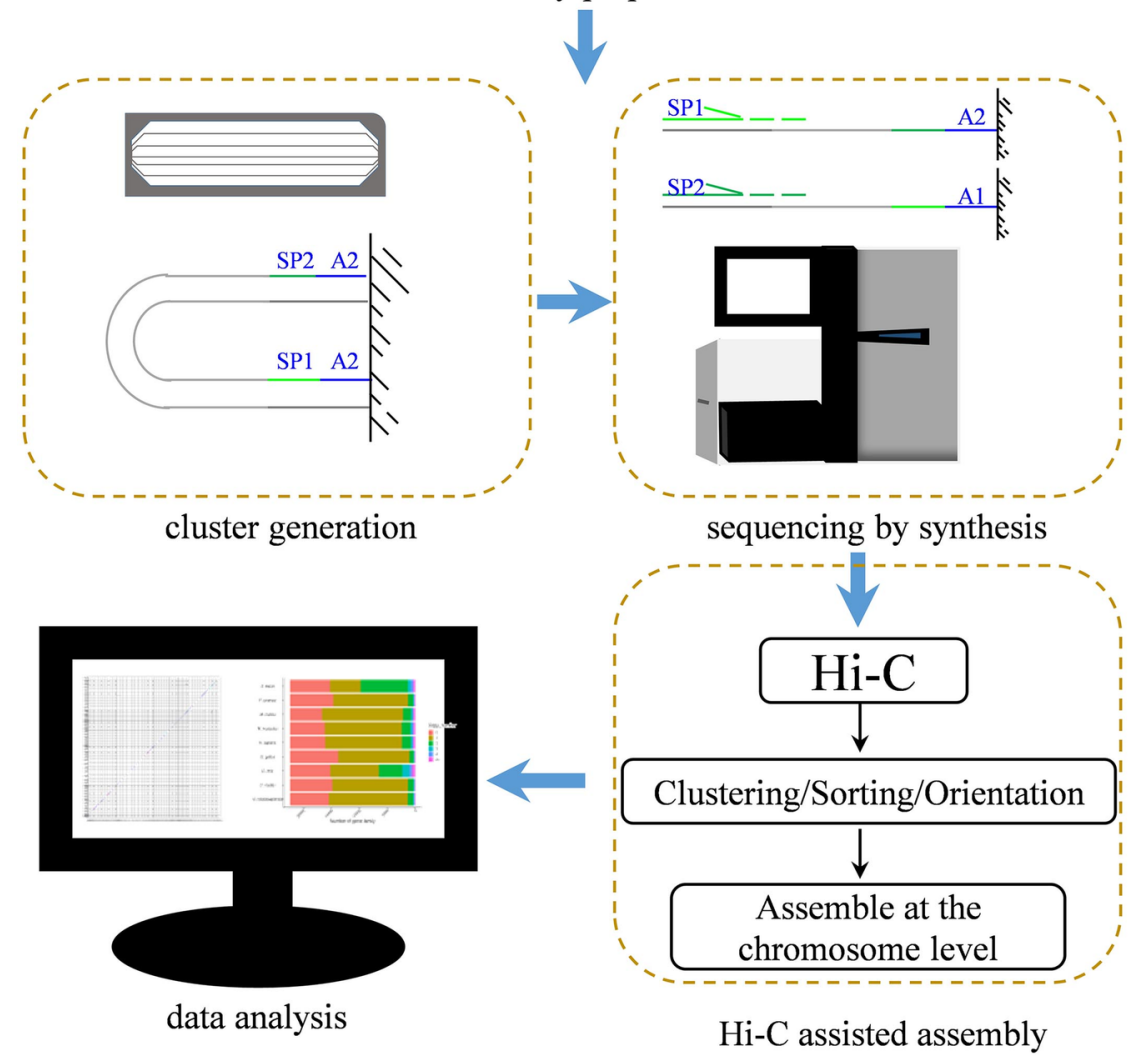



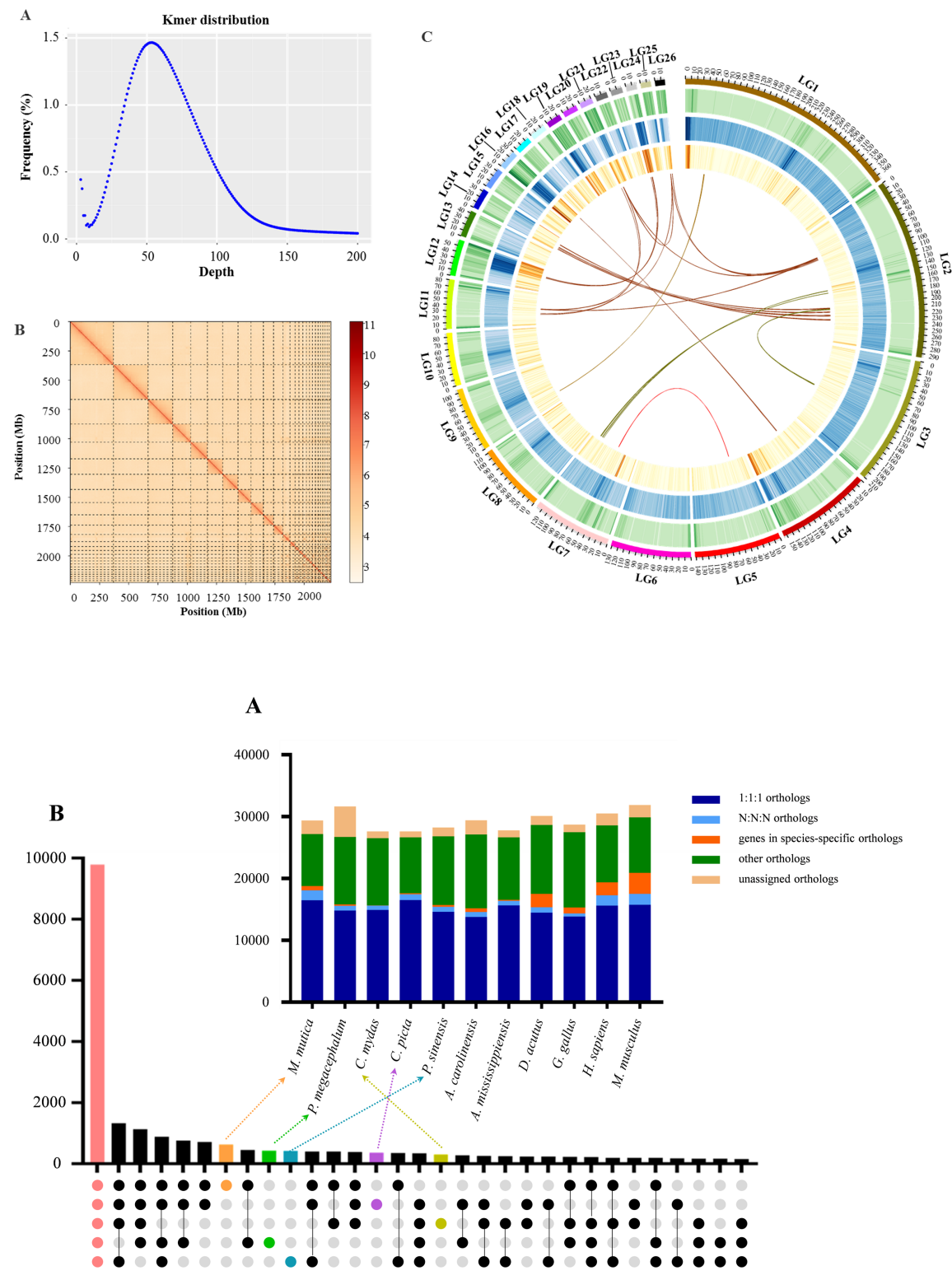

C
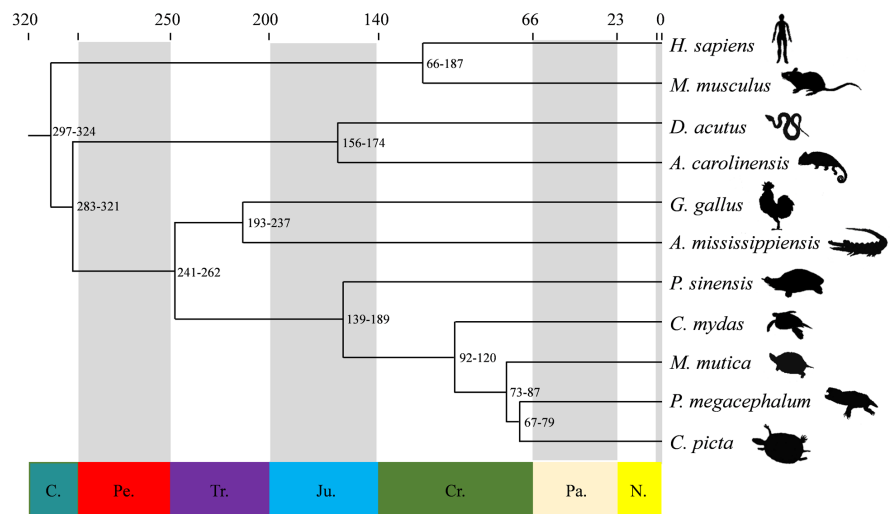


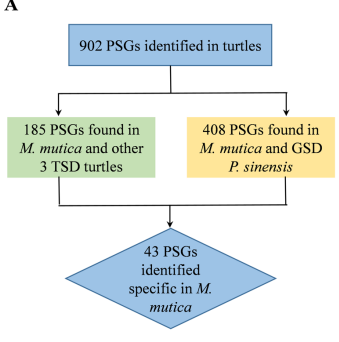

C

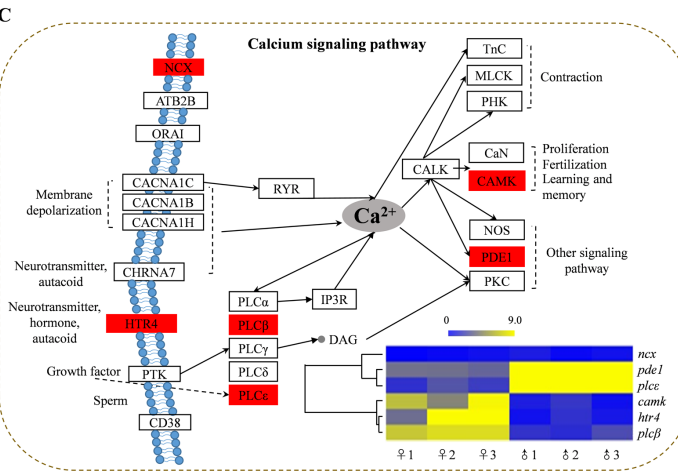

B

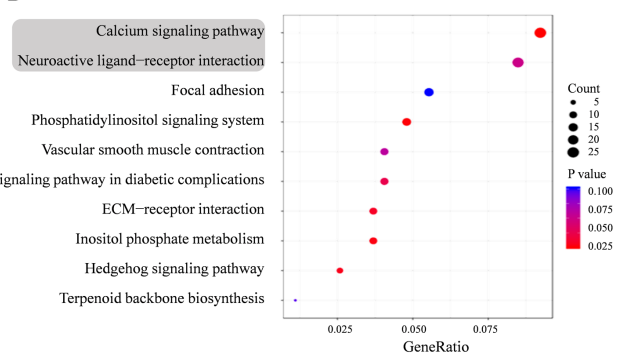

D

Neuroactive ligand-receptor interaction pathway

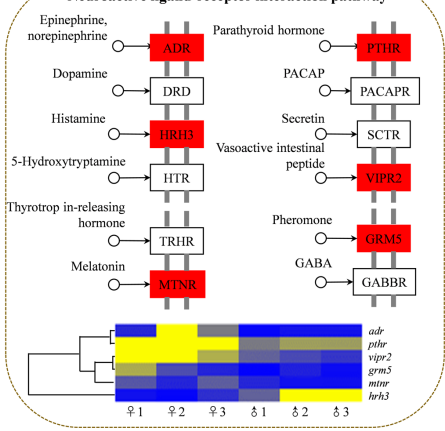

B
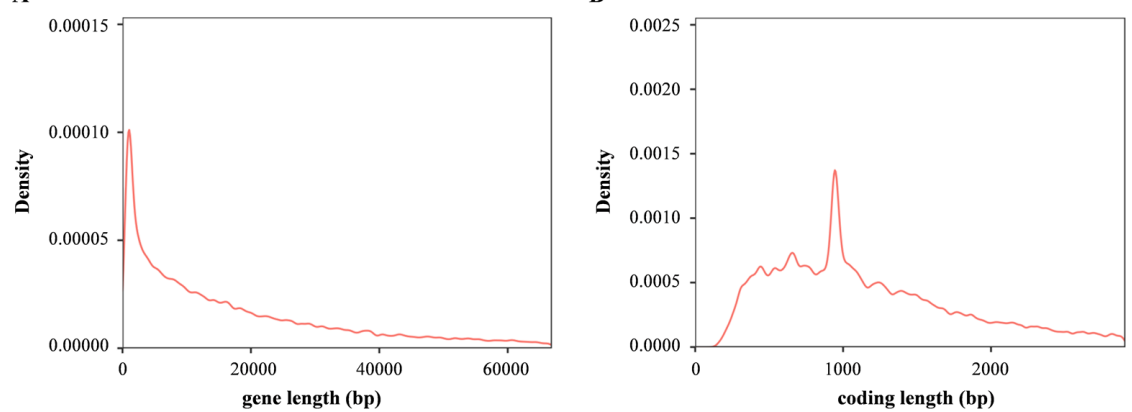

D
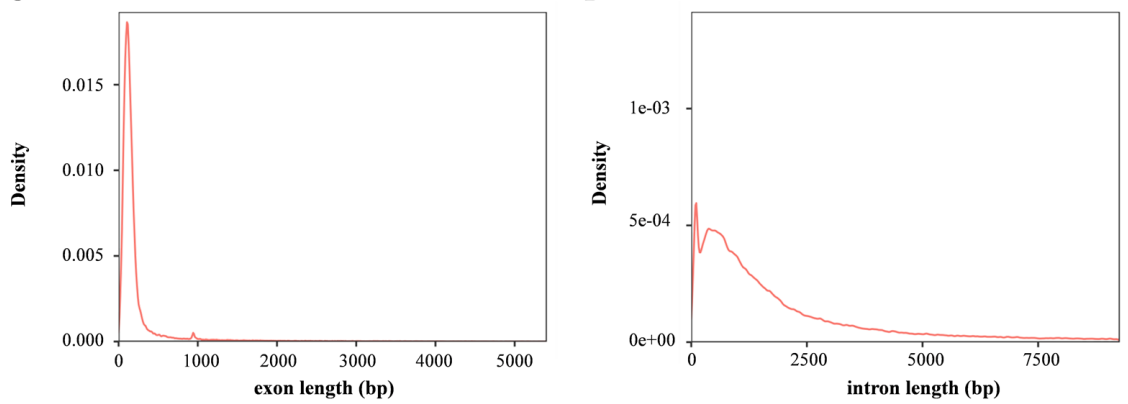


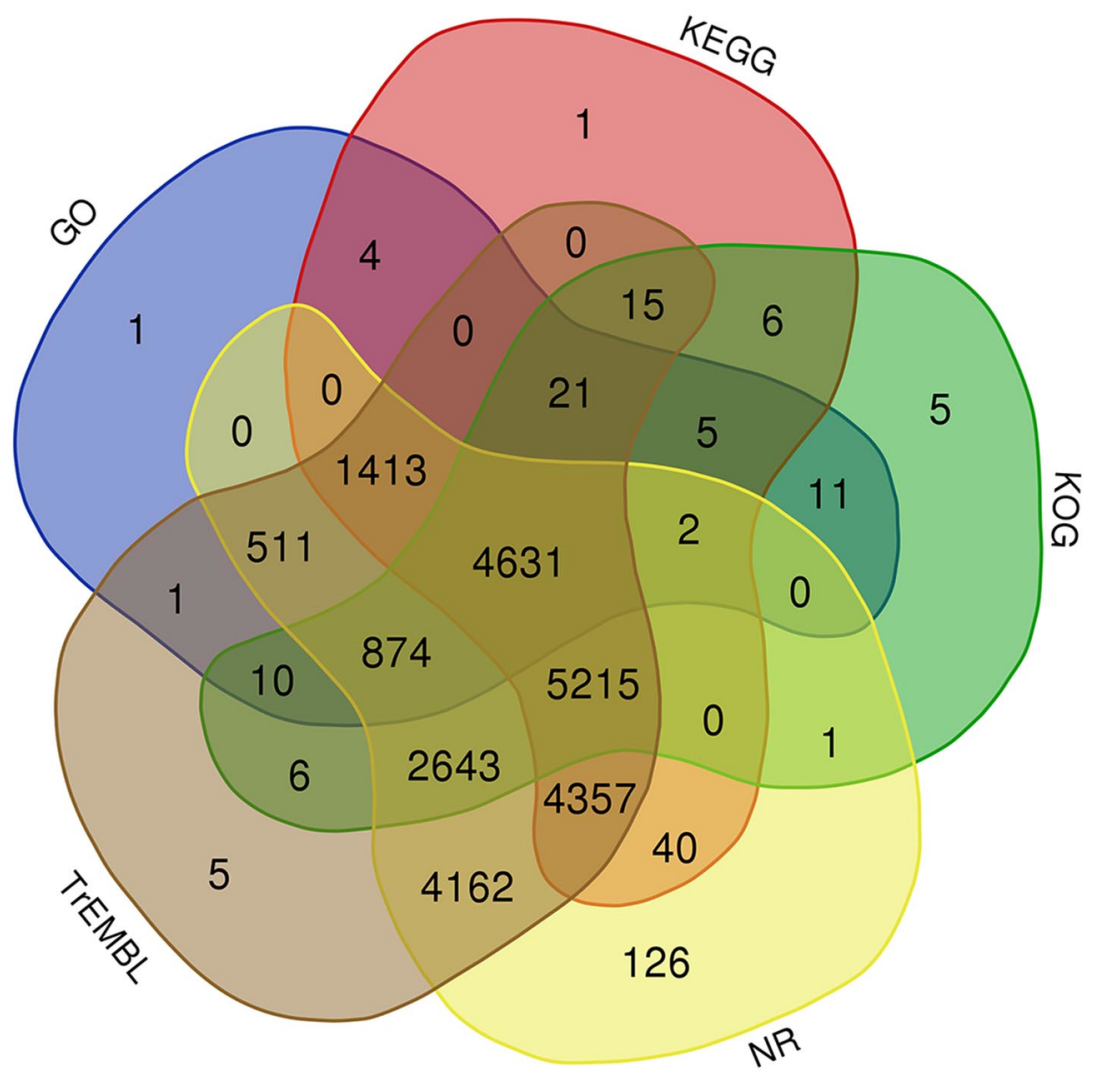


A

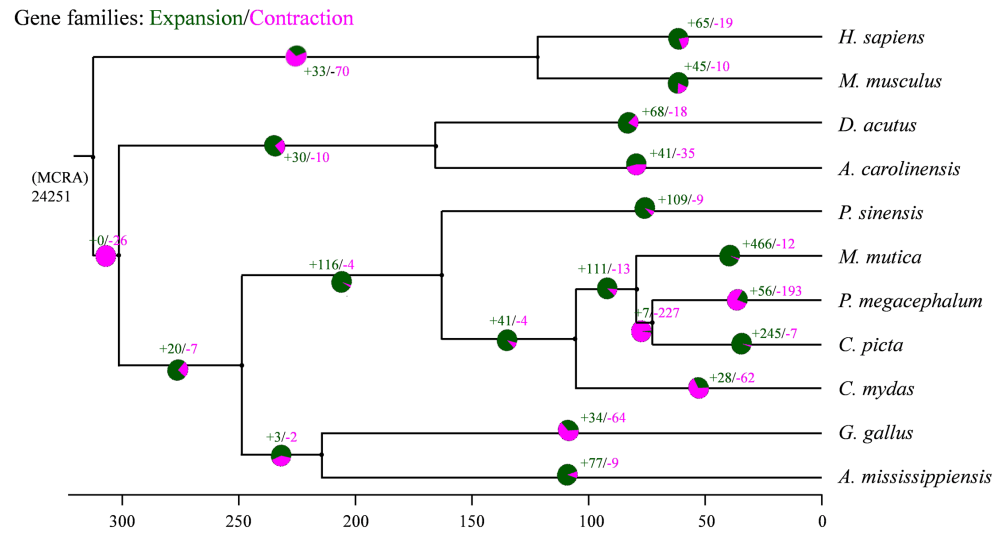

B

C
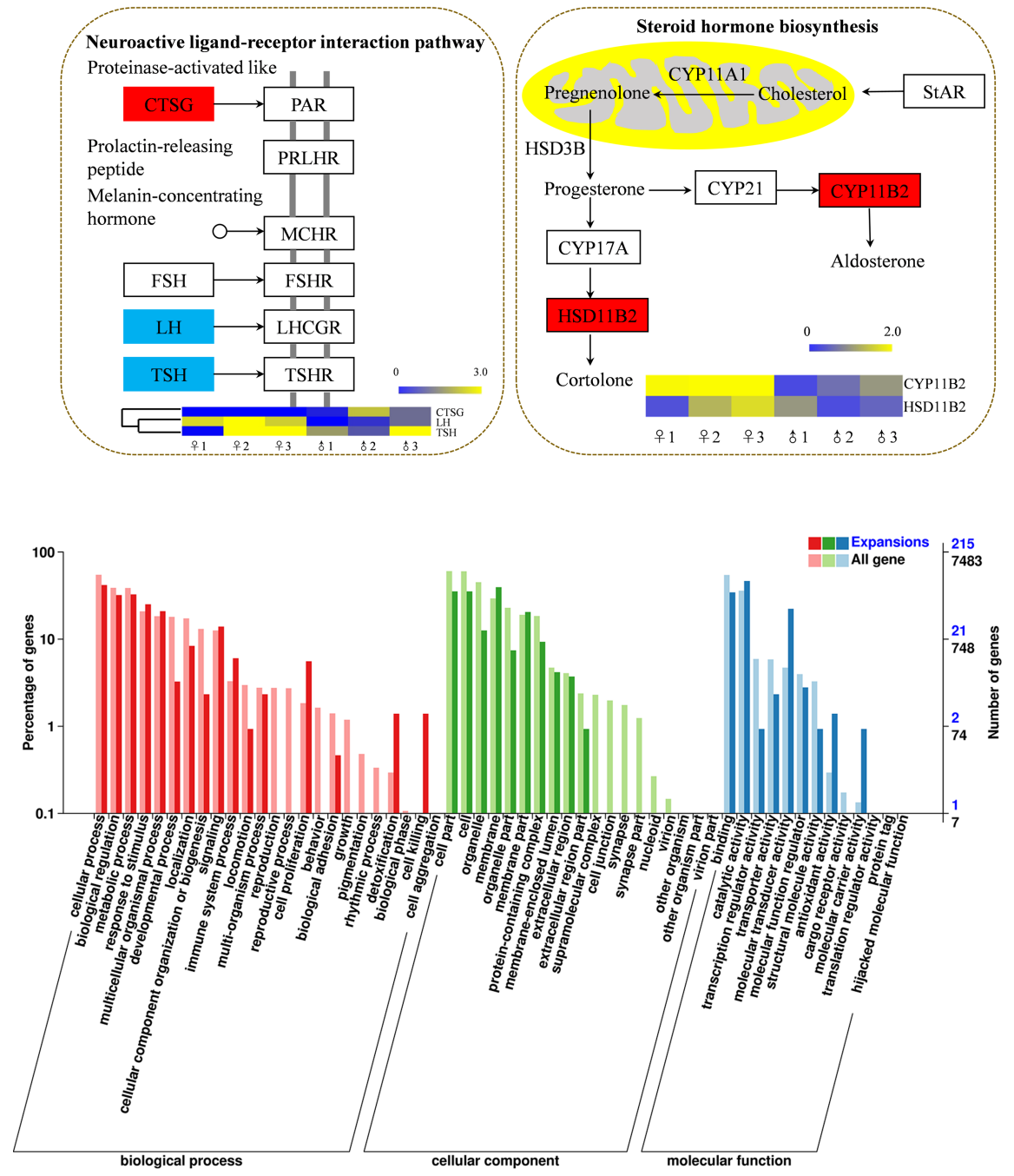

Hosted file

Table 1 and Table 2.docx available at https://authorea.com/users/438552/articles/539739- 
chromosome-level-analysis-of-the-mauremys-mutica-genome-reveals-adaptation-oftemperature-dependent-sex-associated-genes 